\title{
SNP-Based Mapping of Crossover Recombination in Caenorhabditis elegans
}

\section{Grace C. Bazan and Kenneth J. Hillers}

\begin{abstract}
Caenorbabditis elegans is an important experimental organism for the study of recombination during meiosis. Here, we provide methods for the use of single-nucleotide polymorphisms (SNPs) for the study of crossing over in C. elegans.
\end{abstract}

Key words: Crossing over, recombination, PCR, snip-SNP.

\section{Introduction}

Crossing over is a key event during meiosis in Caenorbabditis elegans and many other eukaryotes. Crossovers, in conjunction with sister chromatid cohesion, form the basis of physical connections between homologous chromosomes. These connections play an integral role in helping ensure proper chromosome segregation at meiosis I anaphase. In addition, crossovers result in recombination, the exchange of genetic information between homologous chromosomes. Mapping crossover locations involves detection of these recombination events and necessitates the use of homologous chromosomes that are distinguishable in some way. Here, we summarize approaches for mapping crossovers through the use of single-nucleotide polymorphisms (SNPs) that exist between two laboratory strains of $C$. elegans.

Traditional approaches to mapping crossovers in C. elegans have relied on use of animals heterozygous for morphological markers. The chief limitation of this approach is that studies are 
limited in most cases to two markers (due to the relative paucity of morphological phenotypes in C. elegans). As a result, each experiment typically measures crossover frequency within a single interval, which prevents detection of chromosomes with multiple crossovers and complicates determination of crossover distribution along chromosomes. In addition, some morphological markers can have effects on the viability of homozygotes. An alternative approach, first pioneered by Wicks et al. (1) for gene mapping, involves the use of mapped sequence differences between two laboratory strains of C. elegans.

The wild-type C. elegans strain CB4856 (the Hawaiian strain) differs from wild-type N2 Bristol at approximately $0.1 \%$ of bases. These differences are broadly dispersed throughout the genome and provide a dense array of potential genetic markers for use in measurement of recombination. These markers have the advantage of being phenotypically neutral (in general) and codominant, thus avoiding potential complications due to viability and simplifying scoring. In addition, multiple markers can be followed in a single cross (limited only by the number of PCRs one can carry out on the DNA sample obtained). A subset of these polymorphisms alter (create or destroy) cleavage sites for restriction endonucleases. Such polymorphisms, referred to as snip-SNPs, have been exploited for use in a PCR-based approach for mapping genes and measuring meiotic crossing over (1-3). The basic approaches are similar to those used in traditional recombination studies; however, analysis of marker segregation involves molecular approaches, rather than examination of morphological characters. For more detailed background information and additional technical notes, see (4) and references therein.

A major advantage of this approach is that multiple intervals can be simultaneously assayed for crossing over, allowing determination of the distribution of crossover events along chromosomes and also allowing detection of chromosomes that have enjoyed multiple crossovers. Thus, use of SNP markers has now largely supplanted the use of morphological markers for analysis of crossover distribution in C. elegans $(3,5-12)$. Looking forward, we envision that the use of multiplex approaches for SNP genotyping may supplement current PCR-based approaches for mapping crossovers; an example of such an approach is the Illumina GoldenGate Assay (12). Another recent example involves high-throughput SNP genotyping using SNP-specific primers and qPCR (6). However, these high-throughput approaches tend to be expensive and complicated, requiring specialized equipment and/or reagents. The PCR-based approach described here has the advantage of being both simple and inexpensive; thus, this approach is likely to remain an important method for detecting crossover recombination in C. elegans in the future. 


\section{Materials}

1. $1 \mathrm{M}$ Potassium phosphate buffer, $\mathrm{pH}$ 6.0: $108.3 \mathrm{~g}$ $\mathrm{KH}_{2} \mathrm{PO}_{4}, 35.6 \mathrm{~g} \mathrm{~K}_{2} \mathrm{HPO}_{4}, \mathrm{H}_{2} \mathrm{O}$ to $\mathrm{l}$ 1; autoclave.

2. $5 \mathrm{mg} / \mathrm{ml}$ Cholesterol in $95 \%$ ethanol (do not autoclave).

3. NGM plates: Combine and autoclave: $3 \mathrm{~g} \mathrm{NaCl}, 17 \mathrm{~g}$ agar, $2.5 \mathrm{~g}$ peptone, $975 \mathrm{ml} \mathrm{H}_{2} \mathrm{O}$. Cool to $55^{\circ} \mathrm{C}$. Add and mix well: $1 \mathrm{ml}$ of $1 \mathrm{M} \mathrm{CaCl}_{2}, 1 \mathrm{ml}$ of $5 \mathrm{mg} / \mathrm{ml}$ cholesterol in $95 \%$ ethanol (see above), $1 \mathrm{ml}$ of $1 \mathrm{M} \mathrm{MgSO}_{4}, 25 \mathrm{ml}$ of $1 \mathrm{M}$ potassium phosphate buffer (see above). Dispense into $60-\mathrm{mm}$ Petri dishes, using sterile technique.

4. Escherichia coli OP-50.

5. $10 \mathrm{mM}$ Tris- $\mathrm{HCl}, \mathrm{pH} 8.0$.

6. $10 \mathrm{mg} / \mathrm{ml}$ Proteinase $\mathrm{K}_{\text {in }} \mathrm{H}_{2} \mathrm{O}$.

7. $2 \times$ Single-worm lysis buffer: $100 \mathrm{mM} \mathrm{KCl}, 20 \mathrm{mM}$ Tris$\mathrm{HCl} \mathrm{pH} 8.3,5.0 \mathrm{mM} \mathrm{MgCl}_{2}, 0.9 \% \mathrm{NP}-40,0.9 \%$ Tween$20,0.02 \%$ gelatin. Immediately before use, add proteinase $\mathrm{K}$ to $120 \mu \mathrm{g} / \mathrm{ml}$ (using $10 \mathrm{mg} / \mathrm{ml}$ stock).

8. Reagents for polymerase chain reaction: Taq DNA polymerase and PCR buffer (any supplier); dNTPs (any supplier).

9. Primers: A large and growing number of snip-SNPs have been identified, mostly through the efforts of the Genome Sequencing Center at Washington University at Saint Louis and of Exelixis. Both data sets are available on the Web: http://genome.wustl.edu/ genome/celegans/celegans_snp.cgi (Washington University) and http://www.exelixis.com/discovery_acad_c_ele. shtml (Exelixis). For further information and suggestions on primer design, see (4) and references therein. See also Table 13.1.

10. Restriction digestion master mix: The restriction master mix contains the appropriate restriction enzyme (specific for each snip-SNP marker) and $10 \times$ buffer, plus $\mathrm{H}_{2} \mathrm{O}$. To each $15 \mu \mathrm{l}$ PCR reaction to be digested, add $5 \mu \mathrm{l}$ of a solution containing $2 \mu \mathrm{l}$ of the appropriate $10 \times$ restriction buffer, 3-5 $\mathrm{U}$ of restriction enzyme, and water to make $5 \mu \mathrm{l}$.

\section{Methods}

Section 3.1 gives an overview of the basic approaches used when measuring crossing over using snip-SNP markers, as well as providing information about snip-SNP markers that have been 


\section{Table 13.1}

snip-SNP allele sets for assaying crossovers along each of the six C. elegans chromosomes

\begin{tabular}{|c|c|c|c|c|c|c|}
\hline SNP & Cosmid & Map position & Primer sequence $\left(5^{\prime}-3^{\prime}\right)$ & $\begin{array}{l}\text { Restriction } \\
\text { enzyme }\end{array}$ & $\begin{array}{l}\text { N2 restriction } \\
\text { fragments (bp) }\end{array}$ & $\begin{array}{l}\text { CB4856 restriction } \\
\text { fragments (bp) }\end{array}$ \\
\hline \multicolumn{7}{|c|}{ Chromosome $I^{\mathrm{a}}$} \\
\hline I A & $\mathrm{ZC123}$ & -18.6 & $\begin{array}{l}\text { F: CCTACAACAGGCAAAGAAGC } \\
\text { R: AATTCCTACCAAAGCTCCGC }\end{array}$ & SspI & 643 & 324,319 \\
\hline I B* & Y71G12 & -12.3 & $\begin{array}{l}\text { F: GACAATGACCAATAAGACG } \\
\text { R: GATCCGTGAAATTGTTCCG }\end{array}$ & BsrI & 440,125 & $364,125,76$ \\
\hline I B & F32B5 & -7.7 & $\begin{array}{l}\text { F: TAATGTACCACCTCACGTGACG } \\
\text { R: CTTTCACCAGAACCCTCTATTC }\end{array}$ & $S f u \mathrm{I}$ & 348 & 188,160 \\
\hline I C & K04F10 & 0.9 & $\begin{array}{l}\text { F: ATCATTCTCCAGGCCACGTTAC } \\
\text { R: CTGAACTAGTCGAACAAACCCC }\end{array}$ & $N d e \mathrm{I}$ & 594 & 300,294 \\
\hline I D & T07D10 & 13.6 & $\begin{array}{l}\text { F: CTTGGTGTGGGGAGAGTATAGG } \\
\text { R: TTTGTCCGGATTGACTCTGC }\end{array}$ & Sau3AI & 303,63 & $207,96,63$ \\
\hline I $\mathrm{E}$ & ZK909 & 28.8 & $\begin{array}{l}\text { F: CACAAGTGGTTTGGAAGTACCG } \\
\text { R: CAACAAAGGGATAGATCACGGG }\end{array}$ & HindIII & 450 & 236,214 \\
\hline \multicolumn{7}{|c|}{ Chromosome $I I^{\text {a }}$} \\
\hline II A & T25D3 & -17.9 & $\begin{array}{l}\text { F: CGGAGATAGTCTCGTGGTACTG } \\
\text { R: CAGTCATGCTCCAAACATTCTC }\end{array}$ & DraI & 336,93 & $288,93,48$ \\
\hline II $\mathrm{B}$ & $\mathrm{R} 52$ & -14.5 & $\begin{array}{l}\text { F: TCCATCTTCGCAATCAGATTTC } \\
\text { R: AACGTACTGCTTCCCATGCTC }\end{array}$ & $A h u \mathrm{I}$ & 368 & 203,165 \\
\hline II C & M03Al & -4 & $\begin{array}{l}\text { F: TCATCTGTCGAGTGCTTTTG } \\
\text { R: CGATCGCTCAAATGGTTG }\end{array}$ & TaqI & $291,81,80$ & $210,81,80,70$ \\
\hline II D & F37HB & 3.3 & $\begin{array}{l}\text { F: TTCTCACAACTTCTTTTCCAAG } \\
\text { R: TTCACTATTTCCCTCGCTGG }\end{array}$ & $\operatorname{TaqI}$ & $572,112,15$ & $382,190,112,15$ \\
\hline II E & $\mathrm{Y} 38 \mathrm{Fl}$ & 13.6 & $\begin{array}{l}\text { F: TAGGAAAGTTGTGTCCACCTGG } \\
\text { R: TGATGACTCCTTCTTCAGCTGC }\end{array}$ & $\operatorname{Hinf\mathrm {I}}$ & 449 & 288,160 \\
\hline II F & Y51HI & 20.9 & $\begin{array}{l}\text { F: GATTCGGAATGGGTGTTG } \\
\text { R: TCTTGAATGCGTGGTGTG }\end{array}$ & TaqI & 482 & 340,142 \\
\hline
\end{tabular}




\section{Table 13.1 (continued)}

\begin{tabular}{|c|c|c|c|c|c|c|}
\hline SNP & Cosmid & Map position & Primer sequence $\left(5^{\prime}-3^{\prime}\right)$ & $\begin{array}{l}\text { Restriction } \\
\text { enzyme }\end{array}$ & $\begin{array}{l}\text { N2 restriction } \\
\text { fragments (bp) }\end{array}$ & $\begin{array}{l}\text { CB4856 restriction } \\
\text { fragments (bp) }\end{array}$ \\
\hline \multicolumn{7}{|c|}{ Chromosome III ${ }^{\mathrm{b}}$} \\
\hline III A & T17H7 & -26 & $\begin{array}{l}\text { F: CTGCTTATAGTCTTCCTGTCG } \\
\text { R: GCAACCCСACСTTCAATGAC }\end{array}$ & SspI & 910 & 580,330 \\
\hline III B & $\mathrm{H} 0614$ & -10 & $\begin{array}{l}\text { F: AAACCACCTGAAACTGGAGC } \\
\text { R: CTCGAGATTCTGCGTGAAAC }\end{array}$ & SpeI & 438 & 268,170 \\
\hline III C & F10E9 & 0.5 & $\begin{array}{l}\text { F: AGCAGATGAAAGTTCCGACG } \\
\text { R: CCCCGCTGTGGTTATTATAC }\end{array}$ & $A c c \mathrm{I}$ & 598,225 & 854 \\
\hline III D & T28D6 & 8.5 & $\begin{array}{l}\text { F: TTTCGTGTACGAACGTCTCC } \\
\text { R: CATTTCTCCCACTCTTGCTG }\end{array}$ & DraI & 500 & 283,217 \\
\hline III E & F54F12 & 20 & $\begin{array}{l}\text { F: TTGACTCTTCTGGAGTAGCTGC } \\
\text { R: GGATTCCAGGGATTGAAGAG }\end{array}$ & RsaI & $385,76,11$ & $207,178,76,11$ \\
\hline \multicolumn{7}{|c|}{ Chromosome IV ${ }^{\mathrm{c}}$} \\
\hline IV A & Y38C1AA & -2.7 & $\begin{array}{l}\text { F: AAATAACAGGCACCTACCGC } \\
\text { R: CTTTGAAGGAGGACTAACGG }\end{array}$ & $X b a \mathrm{I}$ & 882 & 481,397 \\
\hline IV B & $\mathrm{F} 52 \mathrm{C} 12$ & -14.9 & $\begin{array}{l}\text { F: ACATTTAGTCACGCGTAGGG } \\
\text { R: GCCCGAATCTAGCACATAAG }\end{array}$ & HpaII & $191,137,22$ & 328,22 \\
\hline IV C & C09G12 & -3.7 & $\begin{array}{l}\text { F: TGTCTACCGTATACCTGGAC } \\
\text { R: ATCCAGCTCAAAAGTGTGCG }\end{array}$ & RsaI & 163,131 & 294 \\
\hline IV D & B0273 & 1.8 & $\begin{array}{l}\text { F: AATACAGCAGTCGTTCCGTTC } \\
\text { R: TGAACTTCATGAACCAGCTTG }\end{array}$ & DraI & 288,144 & 432 \\
\hline IV E & D2096 & 3.8 & $\begin{array}{l}\text { F: ACGAAAAATCACAGAGCGGG } \\
\text { R: AATCAACAACGGACGACGAG }\end{array}$ & $E c o$ RI & 648,326 & 852 \\
\hline IV F & K10D11 & 6.7 & $\begin{array}{l}\text { F: GATTATTTCAGAGGAGCAGAGC } \\
\text { R: CATAGCACGTGGAATAACCAC }\end{array}$ & HindIII & 420 & 245,175 \\
\hline IV G & T02D1 & 16.8 & $\begin{array}{l}\text { F: TGCTTAAAGTCATCGTGTCCAC } \\
\text { R: TGTAAACCGTATCGAATCCGAC }\end{array}$ & EarI & 174,235 & 408 \\
\hline
\end{tabular}




\section{Table 13.1 (continued)}

\begin{tabular}{|c|c|c|c|c|c|c|}
\hline SNP & Cosmid & Map position & Primer sequence $\left(5^{\prime}-3^{\prime}\right)$ & $\begin{array}{l}\text { Restriction } \\
\text { enzyme }\end{array}$ & $\begin{array}{l}\text { N2 restriction } \\
\text { fragments (bp) }\end{array}$ & $\begin{array}{l}\text { CB4856 restriction } \\
\text { fragments (bp) }\end{array}$ \\
\hline \multicolumn{7}{|c|}{ Chromosome $V^{\mathrm{d}}$} \\
\hline V A & Y38C9B & -20.0 & $\begin{array}{l}\text { F: TGTAGGGCGAGTAACCAAGC } \\
\text { R: CCGCACTTCCTTCAGAAATG }\end{array}$ & $\operatorname{BamHI}$ & 318 & 268,50 \\
\hline V B & Hl0Dl8 & -7.9 & $\begin{array}{l}\text { F: ATTGATCCCATGATCTCGG } \\
\text { R: AATCGCTACTTCCGATAACTTC }\end{array}$ & SspI & 436 & 263,173 \\
\hline V C & F57F5 & 3.6 & $\begin{array}{l}\text { F: ATCAATCACATGATGCCGT } \\
\text { R: TTTCAGCTAGACCTCCCATG }\end{array}$ & Hpyl88III & 578 & 326,252 \\
\hline V D & F57G8 & 10.0 & $\begin{array}{l}\text { F: GGCGGAAAGCAATTTCTATC } \\
\text { R: AGCTGCAACCAACACTGCTC }\end{array}$ & DraI & 528 & 272,256 \\
\hline VE & F48F5.2 & 25.00 & $\begin{array}{l}\text { F: GCTTTGGAGACATTGAGCCGTG } \\
\text { R: ATGCTCTTCACATTTTCCTGG }\end{array}$ & Hpyl88III & 439 & 258,181 \\
\hline \multicolumn{7}{|c|}{ Chromosome $X^{\mathrm{a}}$} \\
\hline $\mathrm{X} A$ & $\mathrm{~F} 28 \mathrm{C} 10$ & -19 & $\begin{array}{l}\text { F: GGTATACCGATCCCTTCAACAAG } \\
\text { R: TGGCAAAACACATCCCTGTG }\end{array}$ & $B s p \mathrm{HI}$ & 208,156 & 364 \\
\hline X B & EGAP7 & -15.5 & $\begin{array}{l}\text { F: AGAATCTGGGAGGTAAATGG } \\
\text { R: CCСАTTGAAACTACTCСАССТG }\end{array}$ & $S f c \mathrm{I}$ & 700,246 & 577,369 \\
\hline $\mathrm{X} \mathrm{C}$ & F11D5 & -11.1 & $\begin{array}{l}\text { F: TCGTGGCACCATAACGATGTGG } \\
\text { R: GATTCAGATCAAACAGAGGTGG }\end{array}$ & DraI & 243 & 128,115 \\
\hline X D & F45El & -0.76 & $\begin{array}{l}\text { F: GGTTCCTGGACGATAACGATGTGG } \\
\text { R: CGACCTGAAAGATGTGAGGTTCCTTATC }\end{array}$ & EcoRI & 540,228 & 768 \\
\hline $\mathrm{XE}$ & C05E7 & 10.1 & $\begin{array}{l}\text { F: GGCTCTGAGAAACCAACAAG } \\
\text { R: TGTTTGCGATGACGTGCAG }\end{array}$ & Sau3AI & 318,149 & 467 \\
\hline X F & C33AII & 20.8 & $\begin{array}{l}\text { F: CGAGCAGAGATGCAGAGTTCTCAACTG } \\
\text { R: CGACCTGAAAGATGTGAGGTTCCTTATC }\end{array}$ & HaeIII & 280,300 & 580 \\
\hline
\end{tabular}

${ }^{\mathrm{a}}$ From (10).

${ }^{\mathrm{b}}$ From (7).

${ }^{\mathrm{c}}$ Henzel, Turner, and Hillers, unpublished.

$\mathrm{d}_{\text {From (5). }}$. 
used in previous studies of recombination. Section 3.2 describes a method for measuring crossing over during both oogenesis and spermatogenesis in hermaphrodites using snip-SNP markers. The major advantage of this approach is its simplicity - recombination is assayed by determining the genotype of self-progeny of heterozygous individuals (11). The chief disadvantage of this approach is that crossing over can occur during both sperm and egg production; thus, only a subset of double crossover chromosomes can be unambiguously detected (11).

As an alternative, crossing over can be assayed during meiosis in a single germline; in this case, all double crossover chromosomes can be detected. Section 3.3 describes a method for measuring crossing over during oogenesis in hermaphrodites. This approach has the advantage that each progeny worm assayed represents the product of a single meiosis from the heterozygous hermaphrodite parent; this allows unambiguous detection of all multiply recombinant chromosomes. In addition, the codominant nature of snip-SNP markers means that crossovers can be detected without the additional complication of progeny testing (which is necessary to assay recombination during oogenesis using recessive markers). Therefore, use of snip-SNP markers to assay recombination during oogenesis is preferable to use of traditional recessive morphological markers. Section 3.4 describes a method for measuring crossing over during spermatogenesis in males.

When measuring crossing over in meiotic mutants, it is often necessary to assay crossover formation in many individuals heterozygous for linked genetic markers. This is because mutations affecting meiosis and gametogenesis typically reduce the number of progeny produced, often drastically. Thus, when measuring recombination in meiotic mutants, the following protocols should be modified to involve increased numbers of heterozygous parents.

3.1. Using Snip-SNP Markers to Map Crossovers in Caenorhabditis elegans: Basic Approach
Mapping crossovers relies upon detectable differences between homologous chromosomes. The approach described herein uses single-nucleotide polymorphisms that create or destroy restriction endonuclease recognition sites (referred to as snip-SNPs) as markers for determining the location of crossover events. A large number of SNPs have been identified in the Hawaiian C. elegans strain CB4856; these represent potential markers for use in crossover mapping in animals heterozygous for CB4856- and N2-derived chromosomes. Several online databases exist which summarize identified SNPs (see Section 2 (4)). Davis et al. (13) identified a set of snip-SNPs spanning all chromosomes that can all be analyzed under similar conditions; these represent convenient choices for use as markers to map crossovers. 
A number of studies have used snip-SNPs as markers for crossover detection during meiosis $(3,5,7-11)$. Use of the same markers in future experiments facilitates comparisons between studies. Table 13.1 provides a set of snip-SNP markers on each of the six C. elegans chromosomes, as well as primer sequences and digestion information. These markers have been used in previous studies to map meiotic crossovers (see references in Table 13.1); researchers designing new experiments involving snip-SNP mapping of crossovers could do worse than to use these same markers.

snip-SNPs represent sequence differences between chromosomes that typically are not associated with phenotypic differences; thus, analyzing segregation of snip-SNP markers requires physical detection of the alleles. The basic approach for doing so detailed herein involves amplification of the DNA region containing the snip-SNP through PCR; once amplified, the DNA is digested with a restriction endonuclease whose recognition site is affected by the snip-SNP. Digested DNA is then analyzed through agarose gel electrophoresis. N2- and CB4856-derived DNA can be distinguished by whether or not the restriction endonuclease cleaves the DNA sample (Fig. 13.1).

Using snip-SNP markers to assay meiotic recombination involves production of animals heterozygous for $\mathrm{N} 2$ - and CB4856-derived chromosomes. Doing so in an otherwise wildtype background is simple, requiring only a cross between N2 and CB4856. Use of snip-SNP markers to assay recombination in mutant backgrounds, however, requires introgression of

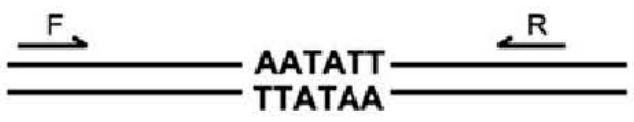

N2 allele (cuts with Sspl)

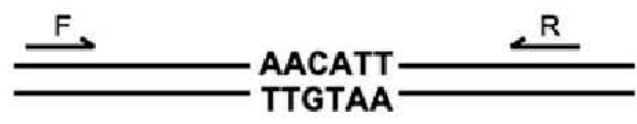

CB4856 allele (does not cut with Sspl)

Amplify snip-SNP - containing region by $P C R$ using primers $F$ and $R$. Digest amplified DNA with Sspl. Analyze by agarose gel electrophoresis.

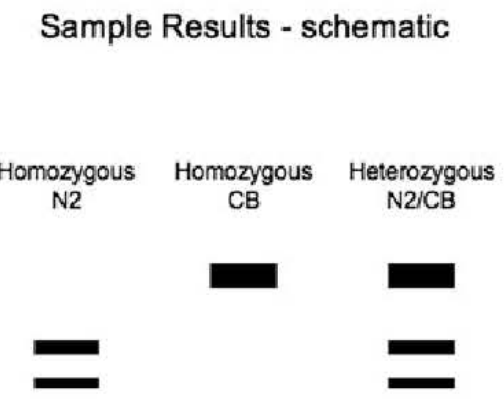

Sample Results - real gel

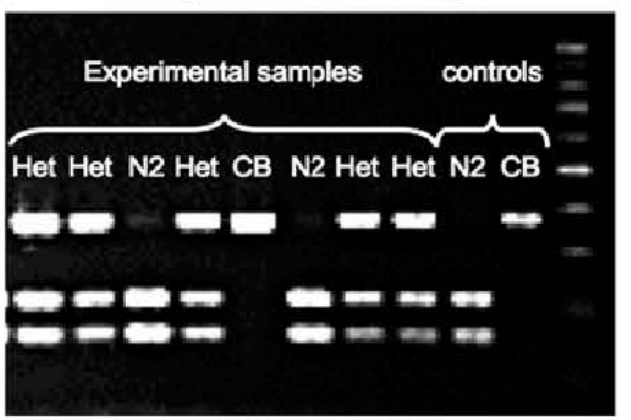

Fig. 13.1. Basic principle of snip-SNP genotyping. snip-SNPs are sequence differences that result in altered sensitivity to a restriction endonuclease (Sspl, in this example). The DNA region containing the snip-SNP is amplified through PCR, using primers that flank the snip-SNP and recognize both N2 and CB4856 DNA. Following amplification, DNA is digested with restriction endonuclease and analyzed through agarose gel electrophoresis. Analysis of bands seen in each lane allows determination of the genotype of the individual tested. See Note 8. 


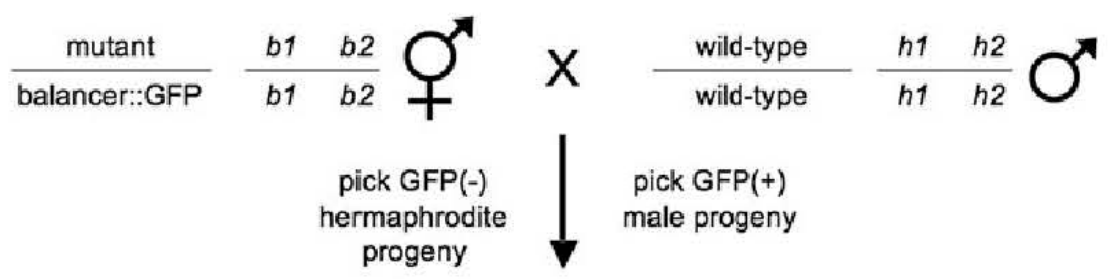

Mate GFP(-) hermaphrodite progeny with GFP(+) male progeny

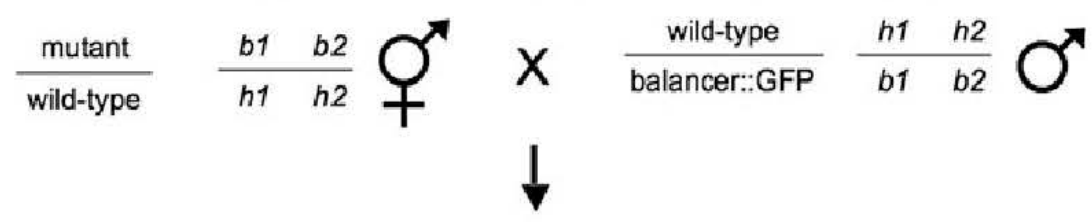

pick GFP(+) hermaphrodite progeny and allow them to self; identify mutant/balancer individuals and screen among their progeny for individuals homozygous for CB4856 alleles on the desired chromosome

Fig. 13.2. Scheme for introgression of CB4856-derived chromosome into mutant background. This scheme assumes that the mutation of interest is balanced by a balancer chromosome that expresses GFP. $b 1$ and $b 2$ are N2-derived snip-SNP alleles; $h 1$ and $h 2$ are CB4856-derived alleles. Note, only two snip-SNP alleles are shown on each chromosome for clarity; SNP-based recombination mapping typically involves 5-6 markers per chromosome.

CB4856-derived chromosomes into the mutant strain through repeated backcrossing. This can be particularly challenging in situations where the mutation has a substantial effect upon fertility or viability. One approach for introgression of CB4856-derived chromosomes into a mutant strain is given in Fig. 13.2.

Once CB4856-derived chromosomes have been introgressed into a meiotic mutant background, the next step is production of animals homozygous for the mutation of interest and heterozygous for N2- and CB4856-derived chromosomes. This is accomplished through crossing, as in Fig. 13.3.

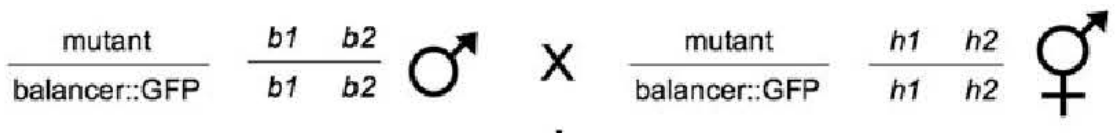

$$
\begin{aligned}
& \begin{array}{c}
\text { pick non-GFP } \\
\text { progeny }
\end{array}
\end{aligned}
$$

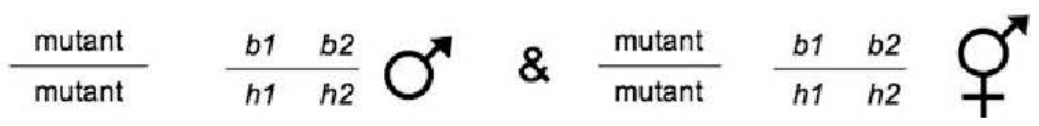

Fig. 13.3. Scheme for production of animals that are both homozygous for a meiotic mutation of interest and heterozygous for snip-SNP markers. Males heterozygous for the mutation of interest ("mutant") and a balancer chromosome marked by a gene insertion which leads to GFP expression ("balancer::GFP") are mated to hermaphrodite partners heterozygous for the mutation of interest (balanced by the GFP-marked balancer chromosome) and homozygous for a chromosome derived from CB4856 (unlinked to the mutation of interest). Male and hermaphrodite progeny from this cross that do not express GFP will be homozygous for the meiotic mutation of interest and heterozygous for the linked phenotypic markers. 


\subsection{Measuring the Incidence of Crossing Over During Both Spermatogenesis and Oogenesis in Hermaphrodites Through the Use of snip-SNP Markers}

Meiotic crossing over can be directly assayed among the self-progeny of $\mathrm{N} 2 / \mathrm{CB} 4856$ heterozygous hermaphrodites (Section 3.2). Alternatively, recombination occurring during oogenesis in hermaphrodites or spermatogenesis in males can be assayed among the outcross progeny of N2/CB4856 heterozygous hermaphrodites or males (Sections 3.3 and 3.4, respectively).

1. Generation of heterozygous hermaphrodites: On a small $(60 \mathrm{~mm})$ NGM plate seeded with E. coli, mate Bristol N2-derived hermaphrodites homozygous for a selected morphological marker to homozygous Hawaiian CB4856 males. After 48 h, remove both male and hermaphrodite parents from the plate and allow progeny to develop (see Notes 1 and 2).

2. Pick heterozygous (phenotypically wild type) Fl hermaphrodites (as L4 or younger) individually to small seeded NGM plates.

3. Move Fl hermaphrodites to new plates every $12-24$ h until they cease producing progeny (see Note 3 ).

4. Scoring markers transmitted to self-progeny: As F2 progeny reach adulthood, pick individually into $0.2-\mathrm{ml}$, thin-walled tubes containing $10 \mu \mathrm{l}$ of $10 \mathrm{mM}$ Tris- $\mathrm{HCl}$, pH 8.0 (see Notes $\mathbf{4}, \mathbf{5}$, and $\mathbf{6}$ ).

5. To each tube, add $10 \mu \mathrm{l}$ of $2 \times$ single-worm lysis buffer and mix well.

6. Lyse worms: Freeze at $-80^{\circ} \mathrm{C}$, incubate at $65^{\circ} \mathrm{C}$ for $1 \mathrm{~h}$ and $95^{\circ} \mathrm{C}$ for $15 \mathrm{~min}$ ( see Note 5 ).

7. PCR analysis: Each snip-SNP marker is amplified using a specific primer pair. Thus, PCR conditions should be empirically optimized for each marker to be analyzed. However, the following general conditions have worked well in our hands: use $0.5 \mu \mathrm{l}$ of worm lysate in each $15 \mu \mathrm{l}$ reaction. PCR cycling: $94^{\circ} \mathrm{C}$ for $2 \mathrm{~min} ; 35$ cycles of $\left\{94^{\circ} \mathrm{C}\right.$ for $20 \mathrm{~s} ; 60^{\circ} \mathrm{C}$ for $30 \mathrm{~s} ; 72^{\circ} \mathrm{C}$ for $40 \mathrm{~s}$; $72^{\circ} \mathrm{C}$ for $10 \mathrm{~min}$ (see Note 7).

8. Restriction digestion: Add an appropriate volume of restriction enzyme master mix to each PCR reaction and digest for $4 \mathrm{~h}$ overnight.

9. Agarose gel analysis: Restriction enzyme-digested PCR products can be analyzed through agarose gel electrophoresis. As expected, DNA fragments are often small (<300 bp), we use $2.5 \%$ agarose gels in $0.5 \times$ TBE.

10. After electrophoresis, score each sample for the presence or the absence of the N2- and CB4856-specific band(s). 
In cases of ambiguity, PCR analysis and restriction enzyme digestion should be repeated. See Note 8 .

11. Identifiable recombinant progeny will fall into two types: (a) those in which crossing over between the assayed markers occurred during production of either sperm or egg but not both. This case results in progeny heterozygous for one marker and homozygous for the other (e.g., $\left[\begin{array}{lll}b 1 & b 2 / b l & b 2\end{array}\right]$, where $b 1$ and $b 2$ represent N2-derived alleles at loci 1 and 2 , respectively, and $h 1$ and $h 2$ represent the CB4856 alleles) and (b) those in which crossing over between the assayed markers occurred during production of both sperm and eggs. Detectable recombinants in this case will be homozygous for recombinant chromosomes (e.g., [ $b 1$ h2/b1 h2]). Note that an equal number of progeny resulting from this case will be heterozygous for both alleles (e.g., [ $b 1$ h2/hl b2]) and thus indistinguishable from non-recombinants.

12. The recombination frequency $(p)$ is calculated using the following equation: $p=1-(1-R)^{1 / 2}$, where $R=$ ( (number of animals heterozygous for one marker and homozygous for the other) $+2 \times$ (number of animals homozygous for recombinant chromosomes))/total number of animals scored (14).

3.3. Measuring the

Incidence of Crossing Over During Oogenesis in Hermaphrodites Through the Use of snip-SNP Markers
1. Generation of heterozygous hermaphrodites: On a small $(60 \mathrm{~mm})$ NGM plate seeded with E. coli, mate Bristol N2derived hermaphrodites homozygous for a selected phenotypic marker to homozygous Hawaiian CB4856 males. After $48 \mathrm{~h}$, remove both male and hermaphrodite parents from the plate and allow progeny to develop (see Notes 1 and 2).

2. Pick heterozygous (phenotypically wild type) Fl hermaphrodites (as L4) individually to small seeded NGM plates along with 5-8 males of N2 background. To aid in identification of outcross progeny, it is often convenient to use GFP-expressing males (see Note 9).

3. After $24 \mathrm{~h}$, each heterozygous hermaphrodite should have mated with the N2 males present on the plate. Thus, progeny produced after $24 \mathrm{~h}$ of mating are likely to be outcross progeny (allowing measurement of crossing over that occurred solely during oogenesis). Move heterozygous hermaphrodites to new plates. Each $24 \mathrm{~h}$ thereafter for several days (or until they cease producing outcross progeny), move individually to fresh plates (see Note 3).

4. Scoring markers transmitted to progeny: As the outcross progeny of the heterozygous hermaphrodite 


\subsection{Measuring Crossing Over in Males Using snip-SNP Markers}

reach adulthood, pick individually into $0.2-\mathrm{ml}$, thinwalled tubes containing $10 \mu \mathrm{l}$ of $10 \mathrm{mM}$ Tris- $\mathrm{HCl}$, $\mathrm{pH} 8.0$ (see Notes 4, 5, 6, and 9).

5. To each tube, add $10 \mu \mathrm{l}$ of $2 \times$ single-worm lysis buffer and mix well.

6. Carry out worm lysis, PCR, restriction analysis, electrophoresis, and scoring as in Section 3.2, steps 6-10.

7. For each interval assayed, outcross progeny will fall into four classes: homozygous $\mathrm{N} 2$ (nonrecombinant; $b 1$ $b 2 / b 1$ b2), heterozygous N2/CB4856 (nonrecombinant; $b 1 \mathrm{~b} 2 / h 1 \mathrm{~h} 2$ ), heterozygous for marker 1 (recombinant; $b 1$ $b 2 / b 1$ b2), and heterozygous for marker 2 (recombinant; $b 1 b 2 / b 1 h 2)$. (b1 and $b 2$ represent N2-derived alleles and $h 1$ and $h 2$ represent CB4856-derived alleles.)

8 . The recombination frequency $p=R$, where $R$ is the fraction of progeny with recombinant genotypes.

1. Generation of heterozygous males: On a small $(60 \mathrm{~mm})$ NGM plate seeded with E. coli, mate Bristol N2-derived hermaphrodites to homozygous Hawaiian CB4856 males (or vice versa). After 24 h of mating, remove all the male parents from the plate, which will facilitate detection of progeny males in step 2 (see Note 2).

2. Pick heterozygous Fl males individually to small seeded NGM plates with several N2-derived late L4 stage hermaphrodites homozygous for some phenotypic mutation (e.g., $u n c-3)$.

3. After $24 \mathrm{~h}$ of mating, transfer the mated hermaphrodite partners (but not the heterozygous males) individually to fresh plates. Each of these animals should have mated with the heterozygous males and will thus produce outcross progeny. Transfer these mated hermaphrodites to fresh plates every $24 \mathrm{~h}$ for several days (or until they cease production of outcross progeny) (see Note $\mathbf{3}$ ).

4. Scoring markers transmitted to progeny: Outcross progeny from mated hermaphrodites will consist of phenotypically wild-type hermaphrodites and males (if the hermaphrodite partners are homozygous for an X-linked marker such as $u n c-3$, outcross males will be mutant (and thus distinguishable from their phenotypically WT fathers)). As outcross progeny reach adulthood, pick individually into $0.2-\mathrm{ml}$, thin-walled tubes containing $10 \mu \mathrm{l}$ of $10 \mathrm{mM}$ Tris- $\mathrm{HCl}, \mathrm{pH}$ 8.0 ( see Notes 4, 5, and $\mathbf{6}$ ).

5. To each tube, add $10 \mu \mathrm{l}$ of $2 \times$ single-worm lysis buffer and mix well. 
6. Carry out worm lysis, PCR, restriction analysis, electrophoresis, and scoring as in Section 3.2, steps 6-10.

7. For each interval assayed, outcross progeny will fall into four classes: homozygous $\mathrm{N} 2$ (nonrecombinant; $b 1$ $b 2 / b 1$ b2), heterozygous N2/CB4856 (nonrecombinant; $b 1 \mathrm{~b} 2 / h 1 \mathrm{~h} 2$ ), heterozygous for marker 1 (recombinant; $b 1$ $b 2 / h 1 b 2$ ), and heterozygous for marker 2 (recombinant; $b 1 b 2 / b 1 h 2$ ). ( $b 1$ and $b 2$ represent $\mathrm{N} 2$-derived alleles and $h 1$ and $h 2$ represent CB4856-derived alleles.)

8. The recombination frequency $p=R$, where $R$ is the fraction of progeny with recombinant genotypes.

\section{Notes}

1. The N2-derived parent in this cross is homozygous for a recessive morphological marker to facilitate identification of outcross progeny, which will be wild type; self-progeny will be a homozygous mutant and thus morphologically distinguishable. This is not necessary but simplifies identification of outcross progeny. Alternative approaches for identification of outcross progeny are detailed in Note 9.

2. Measurement of recombination in animals homozygous for mutations affecting meiosis requires construction of worms homozygous for the meiotic mutation under study and heterozygous for linked genetic markers. However, many meiotic mutants become aneuploid only after a few generations (due to the chromosome missegregation induced by many mutations affecting meiosis); this can greatly complicate both genetic and physical measures of recombination. Thus, it is vitally important to assay recombination in the germlines of euploid mutant animals derived from parents that were heterozygous for the meiotic mutation in question. The simplest approach for doing so involves use of balancer chromosomes marked with a GFP insertion. One way to do so is shown in Fig. 13.3. Note that animals heterozygous for balancer chromosomes should not be used as "wild-type" controls for experiments measuring crossing over in meiotic mutant backgrounds. In balancer chromosome heterozygotes, nonhomologous chromosome synapsis occurs, with subsequent effects on meiotic recombination (e.g., $(15,16))$. For more information about balancer chromosomes in C. elegans, see (17). In cases where a suitable balancer chromosome is not available, worms of the appropriate genotype should be derived as in (18). 
3. A single hermaphrodite produces $250-300$ progeny over a 3- to 4-day period. For measurement of recombination frequencies, it is important to assay all progeny produced by the animal under study during a given time period. By moving hermaphrodites every $24 \mathrm{~h}$, "broods" of roughly 100 progeny are collected. As all of these animals hatched from eggs produced during a single 24 -h period, they will all reach adulthood within a relatively narrow time window (but see Note 4); this greatly simplifies subsequent analyses.

4. As different genotypes may have different growth rates, it is important to score all progeny produced during a given time period; failure to do so may result in undercounting the number of individuals in certain genotypic class(es) and thus reduce the accuracy of the map distance measurement. Thus, each plate of progeny (each "brood"; see Note 3 ) should be checked for progeny multiple times over a span of several days; this will increase the likelihood that all progeny will be scored.

5. At this point, samples can be stored at $-80^{\circ} \mathrm{C}$ until ready for further analysis.

6. Analysis can also be carried out in 96-well plates.

7. Always amplify $\mathrm{N} 2$ and CB4856 controls for amplification and digestion.

8. Incomplete digestion by the restriction endonuclease can give spurious uncut bands, which can complicate analysis of results. Thus, it is important to always include N2 and CB4856 controls for amplification and digestion on each gel. True heterozygotes will have $\mathrm{N} 2$ and $\mathrm{CB}$ alleles in equal abundance. Thus, the uncut band (which is larger and binds more ethidium bromide) will be brighter than the cut bands; for example, see lanes 1 and 2 (from L) in Fig. 13.1. Incomplete digestion can commonly be distinguished from heterozygosity because the smaller bands will be brighter than the larger band, as in lanes 3 and 6 (from L) in Fig. 13.1.

9. To measure the frequency of recombination in the oocyte germline, it is important to only score outcross progeny from the heterozygous hermaphrodite. In crosses of this sort, outcross progeny can be identified in a number of ways:

- Only score hermaphrodite progeny picked from plates with roughly equal numbers of males and hermaphrodites; these should represent outcross offspring. However, if the animals being assayed are mutant for meiotic function, then self-progeny may also have a high proportion of male offspring (the Him phenotype); in that case, use one of the following approaches. 
- Generate outcross progeny using males homozygous for a third, dominant, marker. One example that has been successfully used is the transgene insertion $c c I s 4251$, which expresses GFP under control of the myo-3 promoter (19). In this case, outcross progeny can be distinguished due to GFP expression.

- In experiments measuring recombination in animals homozygous for a deletion allele of a gene of interest (such as a gene involved in meiosis), outcross progeny will be heterozygous for the deletion allele, while self-progeny will be homozygous for the deletion. These genotypes can be assayed by PCR; this allows the researcher a molecular assay to confirm that each progeny animal assayed is truly outcross.

Acknowledgments

Anne Villeneuve helped with the preparation of a previous version of this manuscript. K.J.H. was supported by Award Number RI5HD059093 from the Eunice Kennedy Shriver National Institute of Child Health and Human Development.

\section{References}

1. Wicks, S.R., Yeh, R.T., Gish, W.R., Waterston, R.H., and Plasterk, R.H. (2001) Rapid gene mapping in Caenorhabditis elegans using a high density polymorphism map. Nat Genet 28, 160-164.

2. Hillers, K.J., and Villeneuve, A.M. (2009) Analysis of meiotic recombination in Caenorhabditis elegans. Methods Mol Biol $\mathbf{5 5 7}, 77-97$.

3. Hillers, K.J., and Villeneuve, A.M. (2003) Chromosome-wide control of meiotic crossing over in C. elegans. Curr Biol 13, 16411647.

4. Davis, M.W., and Hammarlund, M. (2006) Single-nucleotide polymorphism mapping. Methods Mol Biol 351, 75-92.

5. Carlton, P.M., Farruggio, A.P., and Dernburg, A.F. (2006) A link between meiotic progression and crossover control. PLoS Genet 2, el2.

6. Lim, J.G., Stine, R.R., and Yanowitz, J.L. (2008) Domain-specific regulation of recombination in Caenorhabditis elegans in response to temperature, age and sex. Genetics $180,715-726$.
7. Mets, D.G., and Meyer, B.J. (2009) Condensins regulate meiotic DNA break distribution, thus crossover frequency, by controlling chromosome structure. Cell 139, 73-86.

8. Nabeshima, K., Villeneuve, A.M., and Hillers, K.J. (2004) Chromosome-wide regulation of meiotic crossover formation in Caenorbabditis elegans requires properly assembled chromosome axes. Genetics 168 , 1275-1292.

9. Saito, T.T., Youds, J.L., Boulton, S.J., and Colaiacovo, M.P. (2009) Caenorhabditis elegans HIM-18/SLX-4 interacts with SLX-1 and XPF-1 and maintains genomic integrity in the germline by processing recombination intermediates. PLoS Genet 5, el000735.

10. Tsai, C.J., Mets, D.G., Albrecht, M.R., Nix, P., Chan, A., and Meyer, B.J. (2008) Meiotic crossover number and distribution are regulated by a dosage compensation protein that resembles a condensin subunit. Genes Dev 22, 194-211.

11. Hammarlund, M., Davis, M.W., Nguyen, H., Dayton, D., and Jorgensen, E.M. (2005) 
Heterozygous insertions alter crossover distribution but allow crossover interference in Caenorhabditis elegans. Genetics 171, 1047-1056.

12. Rockman, M.V., and Kruglyak, L. (2009) Recombinational landscape and population genomics of Caenorhabditis elegans. PLoS Genet 5, el000419.

13. Davis, M.W., Hammarlund, M., Harrach, T., Hullett, P., Olsen, S., and Jorgensen, E.M. (2005) Rapid single nucleotide polymorphism mapping in C. elegans. BMC Genomics 6, 118 .

14. Brenner, S. (1974) The genetics of Caenorhabditis elegans. Genetics 77, 71-94.

15. McKim, K.S., Howell, A.M., and Rose, A.M. (1988) The effects of translocations on recombination frequency in Caenorhabditis elegans. Genetics 120, 987-1001.

16. MacQueen, A.J., Phillips, C.M., Bhalla, N., Weiser, P., Villeneuve, A.M., and Dern- burg, A.F. (2005) Chromosome sites play dual roles to establish homologous synapsis during meiosis in C. elegans. Cell 123, 1037-1050.

17. Edgley, M.L., Baillie, D.L., Riddle, D.L., and Rose, A.M. (April 6, 2006) Genetic balancers In WormBook, The C. elegans Research Community, WormBook, ed. doi/10.1895/wormbook.1.89.1, http:// www.wormbook.org.

18. Kelly, K.O., Dernburg, A.F., Stanfield, G.M., and Villeneuve, A.M. (2000) Caenorbabditis elegans msh-5 is required for both normal and radiation-induced meiotic crossing over but not for completion of meiosis. Genetics 156, 617-630.

19. Fire, A., Xu, S., Montgomery, M.K., Kostas, S.A., Driver, S.E., and Mello, C.C. (1998) Potent and specific genetic interference by double-stranded RNA in Caenorbabditis elegans. Nature 391, 806-811. 